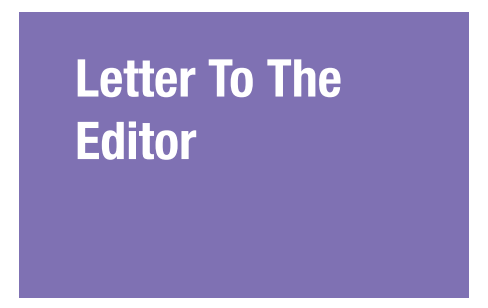

Submitted: 19 Aug 2013

Accepted: 12 Dec 2013

Online: 5 Oct 2016

\section{Corrections of Frequencies of Cytochrome P450 2B6 and 2C8 Allelic Variants in the Mozambican Population}

\author{
Mostafa Saadat
}

Department of Biology, College of Sciences, Shiraz University, Shiraz 71454, Iran

To cite this article: Saadat M. Corrections of frequencies of Cytochrome P450 2B6 and 2C8 allelic variants in the Mozambican population. Malays J Med Sci. 2016;23(5):100-101. http://dx.doi.org/10.21315/mjms2016.23.5.14

To link to this article: http://dx.doi.org/10.21315/mjms2016.23.5.14

To the Editor,

In a recent issue of the Journal, Arnaldo et al., reported the "Frequencies of Cytochrome P450 2B6 and 2C8 Allelic Variants in the Mozambican Population" (1). The authors reported that the frequencies of the allelic variants of the CYP2B6 (OMIM: 123930) and CYP2C8 (OMIM: 601129) genes were found to be homogeneously distributed in the Mozambican population and were comparable to other African populations. I would like to make a few comments about the study.

Base on the "STrengthening the REporting of Genetic Association" studies statement strongly recommended that authors of genetic studies state whether Hardy-Weinberg Equilibrium (HWE), and linkage disequilibrium (for liked polymorphic sites) were considered (2).

Based on the data presented in the second table of the article of Arnaldo et al., the estimations of allelic frequencies of some polymorphisms are not written correctly. Our estimation and estimation of Arnaldo et al., for the allelic prevalence of the minor alleles of the study genetic variations were shown in Table 1.

There were several differences between these two estimations. Because the minor alleles have relatively high prevalence, it is better that we used "variant alleles" instead of "mutant alleles".

I tried to investigate the HWE for each polymorphism. I found that the polymorphisms of c.64C $>\mathrm{T}$ CYP2B6 $\left(\chi^{2}=30.70, \mathrm{df}=1, \mathrm{P}<0.001\right)$, and c.805A $>\mathrm{T} C Y P 2 C 8\left(\chi^{2}=6.34, \mathrm{df}=1, \mathrm{P}=0.011\right)$ were not at Hardy-Weinberg Equilibrium. In the presence of evolutionary pressure, nonrandom mating, problem in the genotyping determination, and errors in the selection of samples, we can observe deviation from the HWE expected frequencies. However, the authors did not mention the deviation from HWE and discussed about it.

Considering that polymorphisms of $\mathrm{CYP} 2 \mathrm{~B} 6$ and $\mathrm{CYP}_{2} \mathrm{C} 8$ are linked, the authors should estimate the linkage disequilibrium and report the D', r2 and prevalence of haplotypes for polymorphic loci.

Therefore, the results of Arnaldo et al., (1) should be interpreted with caution.

Sincerely,

\section{Correspondence}

Mostafa Saadat

$\mathrm{PhD}$ (Shiraz University, Iran)

Department of Biology, College of Sciences, Shiraz University, Shiraz 71454, Iran

Tel: +98-71-36137432

Fax: +98-71-32280916

E-mail: saadat@shirazu.ac.ir; msaadat41@yahoo.com 
Letter To The Editor | Corrections of frequencies

Table 1: Prevalence of minor alleles of polymorphisms at $C Y P 2 B 6$ and $C Y P 2 C 8$ loci

\begin{tabular}{|c|c|c|c|c|}
\hline \multirow{2}{*}{ Polymorphisms } & \multicolumn{2}{|c|}{ Minor alleles frequencies } & \multirow{2}{*}{$c^{2}(d f=1)$} & \multirow{2}{*}{$P$-value } \\
\hline & Arnaldo et al. estimation & Our estimation & & \\
\hline \multicolumn{5}{|l|}{ CYP2B6 gene } \\
\hline c. $64 \mathrm{C}>\mathrm{T}$ & 0.0569 & 0.0583 & 30.70 & $<0.001$ \\
\hline c. $516 G>T$ & 0.426 & 0.4236 & 2.69 & 0.101 \\
\hline c. $785 \mathrm{~A}>\mathrm{G}$ & 0.409 & 0.4069 & 0.91 & 0.338 \\
\hline c.1459C $>$ T & 0.0041 & 0.0041 & 0.01 & 0.936 \\
\hline \multicolumn{5}{|l|}{ CYP2C8 gene } \\
\hline $\operatorname{c.805} \mathrm{A}>\mathrm{T}$ & 0.159 & 0.1625 & 6.34 & 0.011 \\
\hline c. $416 G>A$ & 0.0486 & 0.0486 & 1.17 & 0.190 \\
\hline c. $792 \mathrm{C}>\mathrm{G}$ & 0.0041 & 0.0055 & 0.01 & 0.915 \\
\hline
\end{tabular}

\section{References}

1. Arnaldo P, Thompson RE, Lopes MQ, Suffys PN, Santos AR. Frequencies of Cytochrome P450 2B6 and 2C8 Allelic Variants in the Mozambican Population. Malays J Med Sci 2013;20:13-23.
2. Little J, Higgins JP, Ioannidis JP, Moher D, Gagnon F, von Elm E, Khoury MJ, et al. Strengthening the REporting of Genetic Association studies (STREGA) - an extension of the STROBE statement. Eur $J$ Clin Invest 2009;39:247-266. http://dx.doi.org/10.1111 /j.1365-2362.2009.021 25.x 